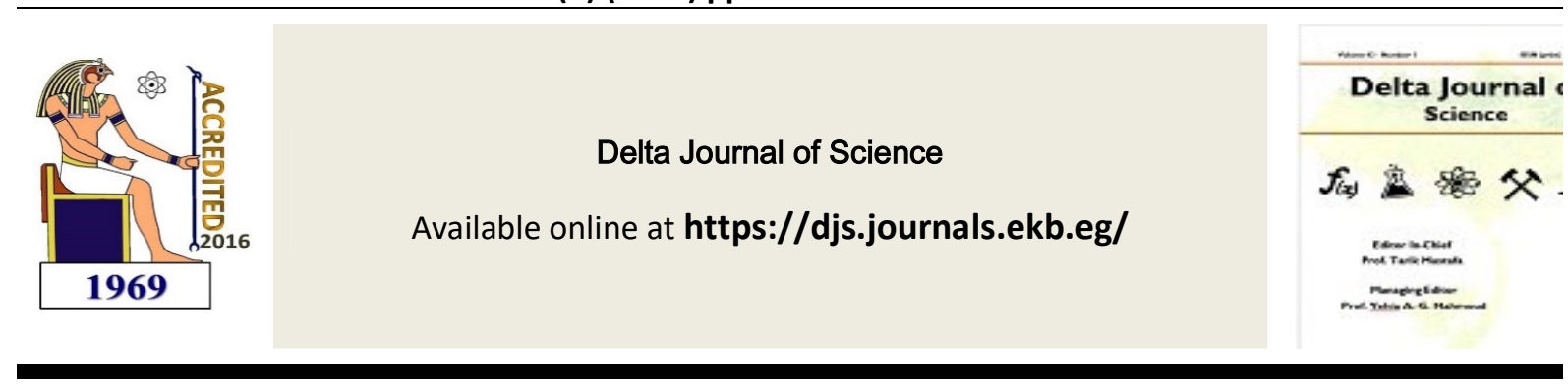

Research Article

CHEMISTRY

\title{
Chemically Crosslinked Polyvinyl Alcohol/ Gelatin Wound Dressing Loaded With Curcumin
}

\author{
El-Refaie Kenawy", Abdelbaset Shoker, Zeinab S. Ghaly, Mahmoud A. El-Meligy \\ * Corresponding author: Prof. El-Refaie Kenawy email: ekenawy@science.tanta.edu.eg
}

\section{KEY WORDS \\ PVA, \\ Gelatin, \\ Chemical \\ crosslinking, \\ Hydrogel \\ membranes, \\ Wound \\ dressings.}

\begin{abstract}
Wound dressings are highly desired for treatment of chronic wound infections. This study aimed to prepare membranes composed of chemically crosslinked PVA and Gelatin polymers. Curcumin was added to improve the membrane biological properties. FTIR spectroscopy was used to investigate their chemical structures, while SEM and TGA analysis were applied to studies the morphology of the membrane and the thermal properties of the crosslinked membranes. In addition, the contact angle measurement was also performed to get more information about the physicochemical properties. In addition, the biodegradability studies were performed and the findings highlighted that the prepared biodegradable PVA/ Gelatin/ Curcumin membranes could be efficiently used as dressers for enhancing the wound healing.
\end{abstract}




\section{Introduction}

Polyvinyl alcohol (PVA) is a linear synthetic polymer produced via partial or full hydrolysis of polyvinyl acetate to convert the acetate groups to hydroxyl groups. The amount of hydroxylation determines the physical characteristics, chemical properties, and mechanical properties of the PVA [1]. The resulting PVA polymer is highly soluble in water but insoluble in organic solvents. The higher the degree of hydroxylation and polymerization of the PVA, the lower the solubility in water and the more difficult it is to crystallize [2]. Due to its water solubility, PVA needs to be crosslinked to form hydrogels for use in several applications. The crosslinks, either physical or chemical, provide the structural stability [3]. The degree of crosslinking dictates the amount of fluid uptake, and thus the physical, chemical, and diffusional properties of the polymer, and ultimately its biological properties.

Gelatin is a soluble protein compound made by partial hydrolysis of collagen, the major fibrous protein constituent in bones, cartilages and skins; therefore, age of the animal, the source, and type of collagen [4].

Gelatin quality for a particular application depends largely on its rheological properties
[5]. Apart from basic physico-chemical properties, such as composition parameters, colour, transparency, solubility, odour and taste, the main attributes that best define the overall commercial quality of gelatin are gel strength and thermal stability (gelling and melting temperatures). For 3 standardizing purposes, measurement of gel strength is determined using the so-called Bloom test, which consists of performing a well-defined protocol at a given gelatin concentration $(6.67 \%)$, temperature $\left(10^{\circ} \mathrm{C}\right)$ and maturation time (17h), thus allowing gel strength to be expressed in the normalized "bloom value" [6]. Both, gel strength and thermostability, are largely dependent on the molecular properties of gelatin, especially with respect to two main factors: (i) the amino acid composition, which is species specific, and (ii) the molecular weight distribution, which results mainly from processing conditions [7].

Curcumin is a hydrophobic polyphenol has antibacterial, antioxidant, antifungal, antiviral, anti-inflammatory, pro-apoptotic and anti-atherosclerotic effects, exerting medicinal benefits against neurodegenerative diseases, arthritis, allergy, inflammatory bowel disease, nephrotoxicity, AIDS, psoriasis, diabetes, multiple sclerosis, cardiovascular disease, and lung fibrosis [8]. 
Current work aims to produce membranes based on both PVA/ Gelatin and including

\section{Experimental}

\subsection{Material}

Polyvinyl alcohol PVA $(\mathrm{Mw}=72,000$ $\mathrm{g} / \mathrm{mol}, 88 \%$ hydrolyzed) was bought from Bioc , Curcumin obtained from Germany, Gelatin from bovine (type B) and Glutaraldehyde (50\%) were obtained from Sigma Aldrich, Germany. Bovine Serum Albumin (BSA, Fraction V).

\subsection{Instruments}

The FT-IR spectra were recorded by (EQUINOX 55 instrument (BRUKER, Germany), contact angle was measured using (advanced Gonimeter model 500-F1), TGA was measured using (Shimadzu TGA 50, Japan), SEM was measured using (FESEM; Zeiss Leo Supra 50 VP). curcumin in these membranes to be used as wound dressing application.

\subsection{Preparation of PVA/ Gelatin/ Curcumin crosslinked membranes}

Polyvinyl alcohol was dissolved in distilled Water with 10\% concentration and mixed with $3 \%$ gelatin solation in distilled water in ratios 5:0, 4:1, 3:2, 2:3 and 1:4 Table (1) then the mixture was stirred at 50 ${ }^{\circ} \mathrm{C}$ for 2 hours. Then Curcumin solution was added to the mixtures to reach final concentration $20 \mu \mathrm{g} / \mathrm{mL}$ followed by addition of $150 \mu \mathrm{l}$ glutaraldehyde $2.8 \%$ was added to the blend of PVA and Gelatin by traditional casting method in petri dishes were need to produce the membranes of PVA/gelatin/ curcumin.

Table (1): Sample codes for different PVA/Gelatin/curcumin membranes

\begin{tabular}{ccc}
\hline Code & $10 \%$ PVA content & Gelatin content \\
\hline $100 \%$ PVA/0\% Gelatin & $25 \mathrm{ml}$ & $0.0 \mathrm{ml}$ \\
\hline $80 \%$ PVA/20\% Gelatin & $20 \mathrm{ml}$ & $5 \mathrm{ml}$ \\
\hline $60 \%$ PVA/40\% Gelatin & $15 \mathrm{ml}$ & $10 \mathrm{ml}$ \\
\hline $40 \%$ PVA $/ 60 \%$ Gelatin & $10 \mathrm{ml}$ & $15 \mathrm{ml}$ \\
\hline $20 \%$ PVA/ 80\% Gelatin & $20 \mathrm{ml}$ & $5 \mathrm{ml}$ \\
\hline
\end{tabular}




\subsection{Gel fraction}

The obtained PVA/ Gelatin/ Curcumin membranes were dried first in a laminar airflow chamber under sterile conditions for $24 \mathrm{hrs}$, then dried again at $50{ }^{\circ} \mathrm{C}$ in vacuum oven for $24 \mathrm{hrs}$ and weighted $\left(\mathrm{W}_{0}\right)$. The dried membrane samples were soaked in distilled water for $24 \mathrm{hrs}$ up to an equilibrium swelling weight (Ws) for removing the leachable or soluble gelatin parts from membrane. The membrane then dried directly at 50 ${ }^{\circ} \mathrm{C}$ in vacuum oven and weighted again (We). The gel fraction (GF \%) was calculated by the following equation [9]

Gel fraction GF \% $=\left(\mathrm{We}_{\mathrm{W}} / \mathrm{W}_{0}\right) \times 100$

\subsection{Swelling behavior}

In order to measure the swelling degree of PVA/ Gelatin/ Curcumin membranes, the membrane samples were cut into 2x $2 \mathrm{~cm}$ pieces and dried at 50 ${ }^{\circ} \mathrm{C}$ in an oven for $24 \mathrm{~h}$, the weight of dried sample was determined (We). The dried samples were soaked in distilled water, maintained and incubated at $37^{\circ} \mathrm{C}$, then weighted (Ws) at specific interval times. The water uptake of PVA/ Gelatin/ Curcumin membranes was determined using the following formula [9].

Water uptake or swelling ratio

$$
\mathrm{SR} \%=[(\mathrm{Ws}-\mathrm{We}) / \mathrm{We}] \times 100
$$

\subsection{Biodegradability}

Biodegradability of the membrane was measured by the following method, PVA/ Gelatin/ Curcumin membranes have been dried under vacuum at $50{ }^{\circ} \mathrm{C}$ for $24 \mathrm{~h}$. dried membrane samples with size of $15 \times 8 \mathrm{~mm}$, were weighted and immersed in $3 \mathrm{ml}$ phosphate buffer saline $\left(0.1 \mathrm{M}, \mathrm{pH} 7.4\right.$, at $\left.37^{\circ} \mathrm{C}\right)$. The samples were removed at timed intervals and then wiped gently with soft paper to remove surface water. The samples were dried again under the same mentioned drying conditions above and finally weighted. All experiments were done in triplicate.

\subsection{Wettability (Contact angle measurements)}

Static water contact angle measurements were performed at room temperature using (advanced Gonimeter model 500-F1) in a sessile drop configuration (using ultrapure water as the liquid), coupled with a video camera and image analysis software. At least ten droplet images were obtained for each film [10].

\subsection{FT-IR}

Vacuumed and dried samples of PVA, Gelatin, Curcumin and PVA/ Gelatin/ Curcumin membranes were analyzed by FTIR on an EQUINOX 55 instrument (BRUKER, Germany). Translucent KBr-disks were prepared by 
grinding the dried sample materials together with infrared grade $\mathrm{KBr}$ and then pressing. The FTIR spectra were obtained by recording 64 scans between 4000 and $400 \mathrm{~cm}^{-1}$ with a resolution of 2 $\mathrm{cm}^{-1}$. All samples were freeze-dried using liquid nitrogen, crushed to a fine powder (KBr: sample $=140 \mathrm{mg}: 2 \mathrm{mg}$ ), and pressed by applying a force $105 \mathrm{~N}$ into a transparent disk (maximum disk weight $=145 \mathrm{mg}$ ) with a diameter of 13 mm. All samples were measured in absorbance mode.

\subsection{Thermogravemetric analysis}

(TGA)

The samples were subjected to TGA instrument to determine their thermal stability and decomposition characteristics. Thermal stability of the polymer films was examined, using thermogravimetric analyzer (Shimadzu TGA -50, Japan).

\subsection{Scanning electron microscope}

The surface morphology of the dried Gelatin layers was investigated using field-emission scanning electron microscopy (FE-SEM; Zeiss Leo Supra $50 \mathrm{VP})$. Before characterization, the samples were sputtered with a thin (B5 $\mathrm{nm})$ gold layer to avoid electron charging effects during FE-SEM characterization. The gold-coated samples were then fixed on metallic stubs using a conductive carbon tape and placed into the vacuum chamber of the microscope for image capturing.

\section{Results and discussion}

\subsection{PVA stabilization forming hydrogel membranes}

Fig. (1) represented photos of the formed chemically crosslinked films that formed after casting the PVA in Petri dishes with glutaraldehyde.

Addition of glutaraldehyde to PVA was made chemical crosslinking with PVA by forming chemical bonds as a bridge and convert membranes from soluble to be crosslinked insoluble membranes as shown in Fig. (2).

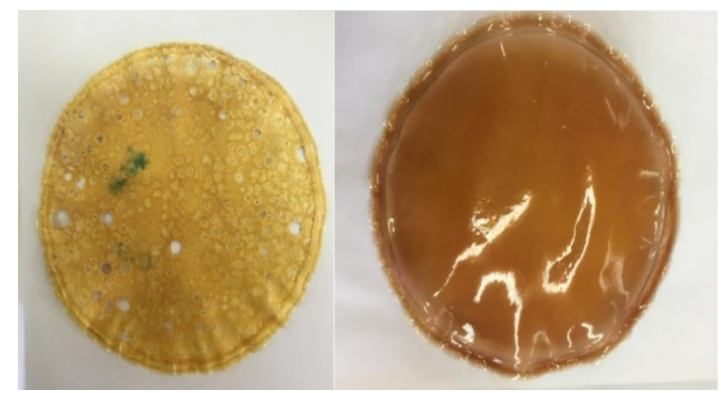

Fig 1: Photos of the prepared membranes

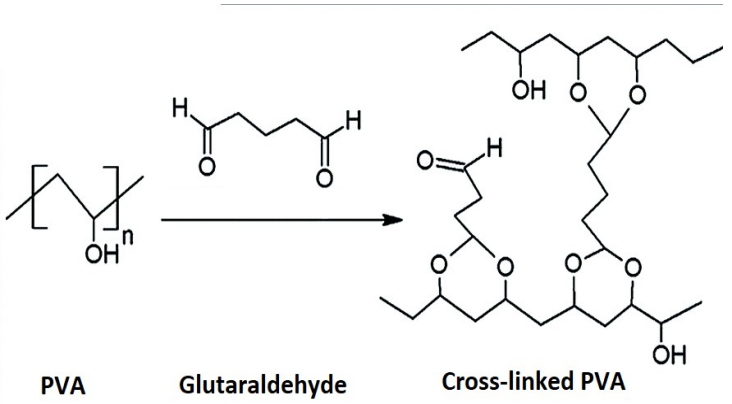

Fig. (2): Crosslinking between PVA and glutaraldehyde 


\subsection{Gel fraction}

Fig. (3) represented gel fraction of crosslinked PVA/ Gelatin/ Curcumin membranes and it was appeared that the highest PVA content had the highest crosslinking degree and highest stability and incorporation of gelatin in content of membranes decreasing gel fraction percent and the highest gelatin content had the least crosslinking degree which confirm PVA crosslinking after glutaraldehyde addition.

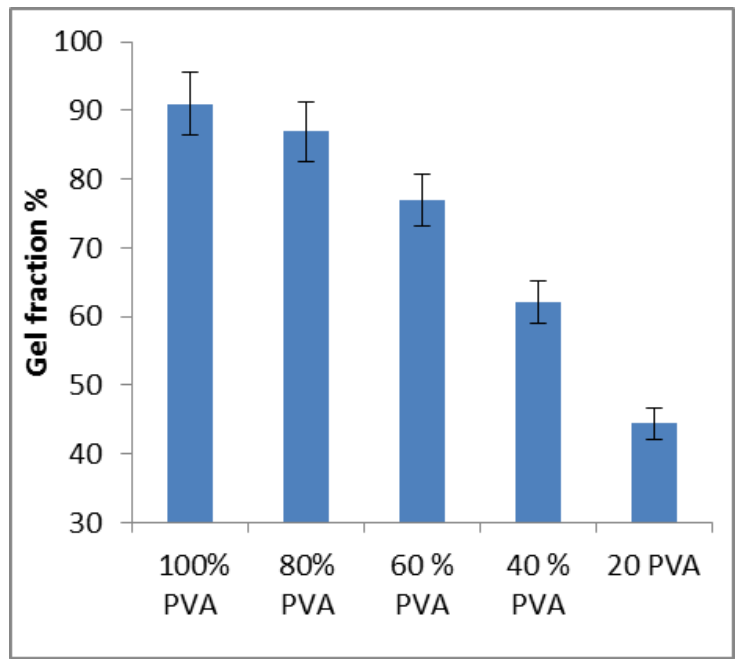

Fig. (3): Gel fraction of PVA/ Gelatin incorporated Curcumin crosslinked membranes graph.

\subsection{Swelling behavior}

Fig. (4) illustrated the water uptake for PVA/ Gelatin/ Curcumin crosslinked membranes, it was clear that membranes of only PVA containing Curcumin had the least water uptake and incorporation of gelatin in the content of PVA/ Curcumin membranes increased their swelling behavior and by increasing the content of gelatin increased the water absorbability of prepared membranes

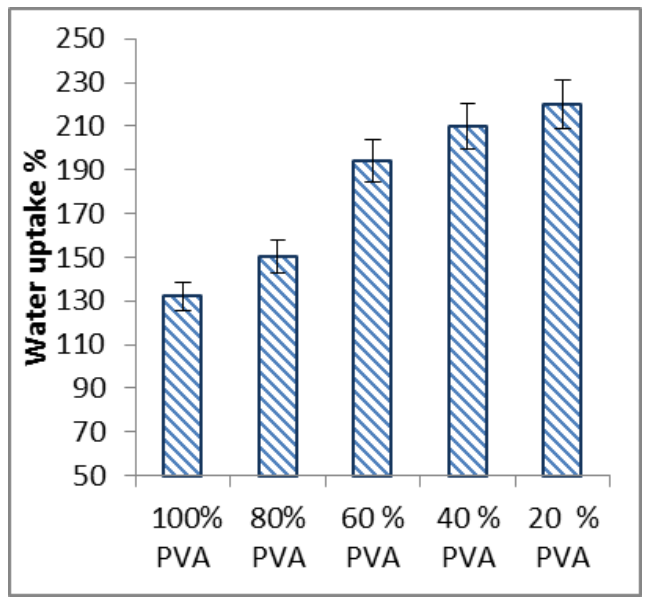

Fig. (4): water uptake of PVA/Gelatin incorporated Curcumin crosslinked membranes graph

\subsection{Biodegradability}

The hydrolytic degradation mechanism investigated in this study explained the degradation of native PVA and Gelatin and their contents in crosslinked membranes because the initial membranes had a smooth interface, allowed water to easily permeate to the inner side after immersion in PBS, resulting in rapid degradation from the outside to the inside and promoting weight loss. Membrane surface macromolecules preferentially hydrolyze into low molecules that were dissolved in PBS, and the degradation pattern is largely surface erosion [11].

It was appeared that from the following diagram in Fig. (5) that the prepared membranes from 100\% PVA almost non degradable and the loss weight percent 
around $1-1.2 \%$ and incorpoaration of Gelatin in PVA/ Curcumin membranes slightly increase the biodegrabiliity until content of Gelatin reach $44 \%$ and more produce highly biodegradable membranes which confirm our results of Gel fraction degree and the samples with chemically crosslinking using glutaraldehyde.

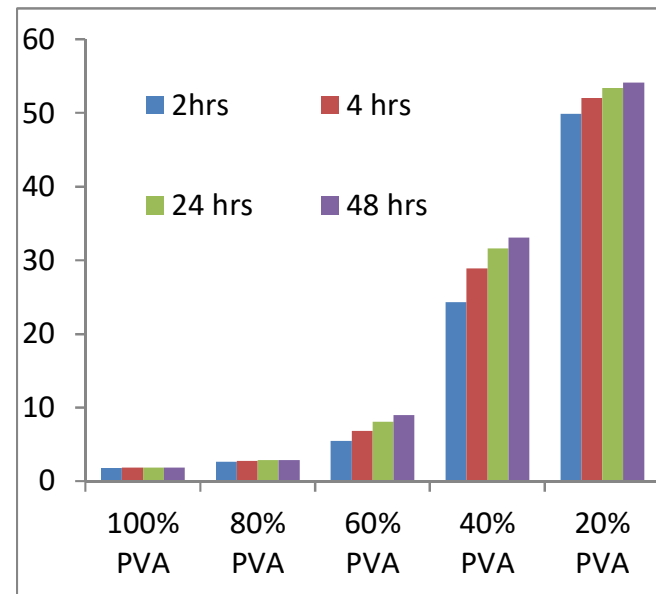

Fig. (5): Biodegradability of PVA/ Gelatin incorporated Curcumin stabilized hydrogel membranes.

\subsection{Wettability (contact angel)}

Contact angel of PVA stabilized hydrogel membranes of $100 \%$ PVA content show highest contact angel value of electro spraying small droplets which was $81.2^{\circ}$ which dramatically decreased to reach $31.7^{\circ}$ for the lowest PVA content and highest $80 \%$ Gelatin extract content as represented in Fig. (6). The results confirmed the data resulted from swelling experiment that the hydrophilicity increased with increasing the content of Gelatin and decreasing PVA crystalized via glutaraldehyde. Fig. (7) showed the photos resulted from electro spraying small droplets.

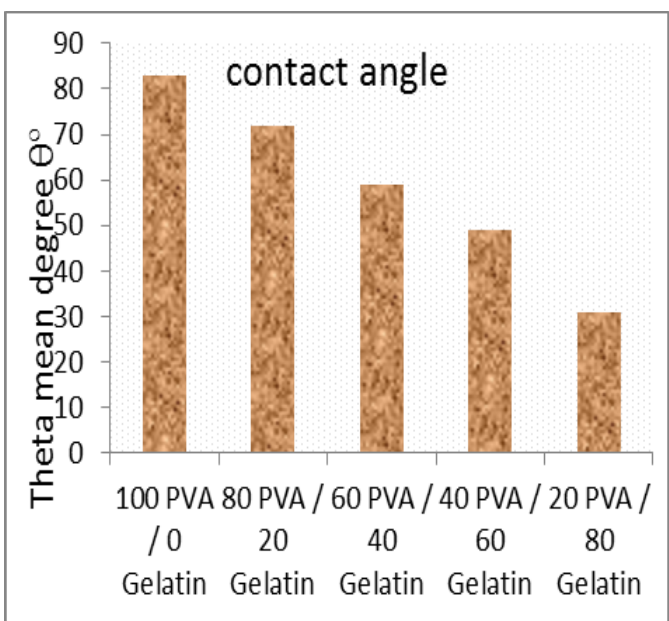

Fig. (6): graph of contact angel results for PVA/ Gelatin incorporated Curcumin stabilized films

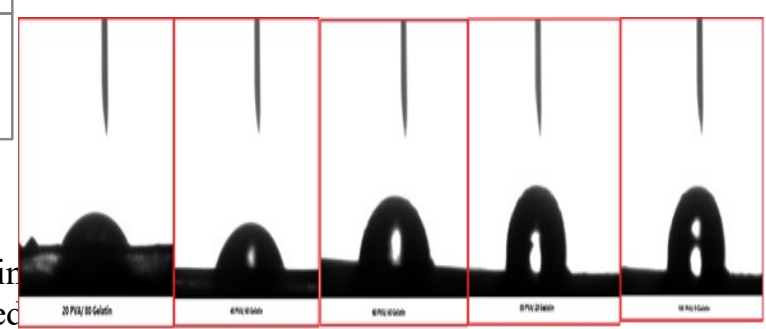

Fig. (7): photo of electro spraying small droplets on different membrane contents

\subsection{FT-IR}

Fig. (8), pure PVA, The $-\mathrm{OH}$ stretching vibration was responsible for the band at $3301 \mathrm{~cm}^{-1}$, whereas the $\mathrm{OH}$ bending vibration of the hydroxyl group is responsible for the peak at $1425 \mathrm{~cm}^{-1}$. Asymmetric $\mathrm{CH}_{2}$ group stretching vibration was shown by the vibrational band at $2925 \mathrm{~cm}^{-1}$. The $\mathrm{C}=\mathrm{C}$ stretching vibration of PVA was responsible for the 
peak at around $1633-1561 \mathrm{~cm}^{-1}$. The $\mathrm{C}-$ $\mathrm{O}$ stretching vibration had a peak at roughly $1089 \mathrm{~cm}^{-1}$, while the $\mathrm{C}-\mathrm{C}$ stretching vibration had a band around $842 \mathrm{~cm}^{-1}[12,13]$.

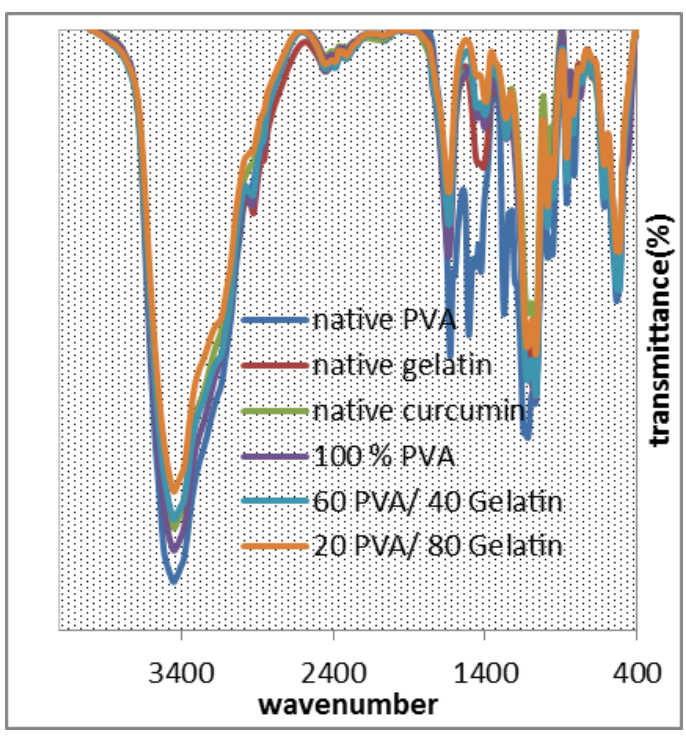

Fig. (8): FT-IR graphs of PVA/Gelatin stabilized films with different contents

The IR spectra of Curcumin, shows stretching vibrations at $1628 \mathrm{~cm}^{-1}$ attributed predominantly to the overlapping stretching vibrations of alkenes $(\mathrm{C}=\mathrm{C})$ and carbonyl $(\mathrm{C}=\mathrm{O})$ character. Infrared of Curcumin ligand showed stretching vibration at 3200 $3500 \mathrm{~cm}^{-1}$ due to $\mathrm{O}-\mathrm{H}$ groups, $\mathrm{C}=\mathrm{C}$ aromatic stretching vibration at $1427 \mathrm{~cm}^{-}$ 1 and high intensity band at $1512 \mathrm{~cm}^{-1}$ attributed to the mixed vibrations including stretching carbonyl bond vibrations $v(\mathrm{C}=\mathrm{O})$, in plane bending vibrations around aliphatic $\delta \mathrm{CC}-\mathrm{C}, \delta$ $\mathrm{CC}=\mathrm{O}$ and in plane bending vibrations around aromatic $\delta \mathrm{CC}-\mathrm{H}$ of keto and enol configurations and stretching vibrations around aromatic $\mathrm{vCC}$ bonds of keto and enolic form of Curcumin [14]. Furthermore, significant intense band at $1277 \mathrm{~cm}^{-1}$ attributed to the bending vibration of the $v(\mathrm{C}-\mathrm{O})$ phenolic band.

The FTIR spectra of gelatin exhibited peaks at $3450 \mathrm{~cm}^{-1}$ and $3423 \mathrm{~cm}^{-1}$ due to secondary amide $-\mathrm{NH}$ stretching, $\mathrm{C}=\mathrm{O}$ stretching at $1680 \mathrm{~cm}^{-1}$ and $1640 \mathrm{~cm}^{-1}$, and $\mathrm{C}=\mathrm{O}$ stretching at $1680 \mathrm{~cm}^{-1}$ and $1640 \mathrm{~cm}^{-1}$. $-\mathrm{NH}$ bends between 1550 and $1500 \mathrm{~cm}^{-1}$. C-H stretching at 2922 $\mathrm{cm}^{-1}$ and $2850 \mathrm{~cm}^{-1}$ and -NH out-ofplane wagging at $670 \mathrm{~cm}^{-1}$ [15].

\subsection{Thermogravemetric analysis (TGA)}

TGA thermograms various amounts of PVA/ Gelatin based membranes containing Curcumin showing changes in thermal degradation profile as loss weight percent and the concluded thermogram data have been complied in Table (2).

Table (2): Thermogravemetric results of PVA/ Gelatin/ Curcumin crosslinked membranes

\begin{tabular}{|cccc}
\hline & T25 & T50 & T75 \\
\hline 20 PVA/ 80 Gelatin & 342 & 375.37 & 454 \\
\hline 40 PVA/ 60 Gelatin & 338 & 377 & 447 \\
\hline 60 PVA/ 40 Gelatin & 331 & 367 & 438 \\
\hline 80 PVA/ 20 Gelatin & 307 & 359.8 & 410 \\
\hline 100 PVA/ 0 Gelatin & 275 & 293.55 & 332 \\
\hline
\end{tabular}

The thermal decomposition temperature (T25, T50 and T75) have been studied. 
As gelatin content increased, the residual weight loss after complete volatilization and the onset temperatures slightly increase Fig. (9), and Table (2). Thus, addition of gelatin improved the thermal stability of PVA/ Gelatin/ Curcumin membranes, because the hydroxyl groups of gelatin might form hydrogen bonding with those of PV

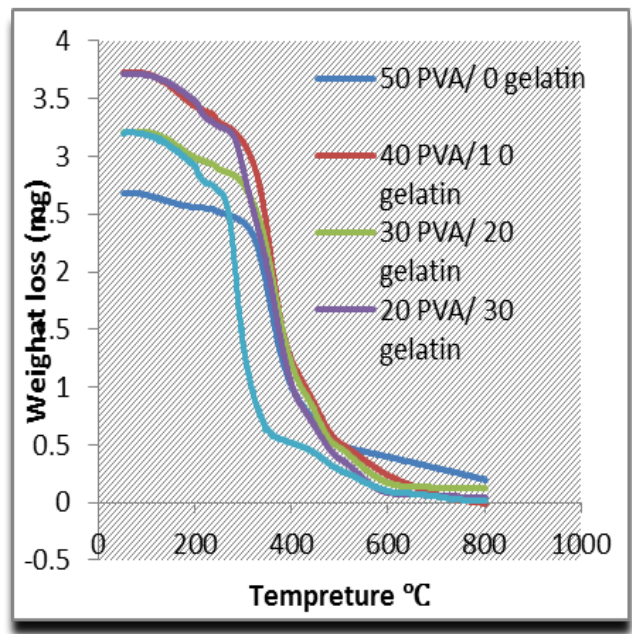

Fig. (9): TGA thermogram of PVA/ Gelatin stabilized hydrogel films.

The first degradation step at $50-150{ }^{\circ} \mathrm{C}$ could be ascribed to the removal of traces of water or solvent vapor. The second degradation step between 250 and $500{ }^{\circ} \mathrm{C}$ resulted in the highest residual weight loss and this was due to the decomposition and volatilization of organic components of polymer. The third decomposition step was after approximately $550{ }^{\circ} \mathrm{C}$, the curves all become flat and mainly the organic residues are completely volatilized.
The presented data of thermal degradation in Table 2 [9] who revealed that the addition of HES to PVA improved thermal properties of hydrogels.

\subsection{Scanning electron microscope morphological study}

Scanning electron micrographs revealed that the film morphology of highest Gelatin content had more destroying surface and more amorphous surface and cross-sectional shape but the higher PVA hydrogel membrane content gave more arranged surface and some vertical stacks like tubes or channels in cross-sectional shape as illustrated in Figs. (10, 11) from Fig. (10) also it was clear that the highest gelatin content sample had a highest porous surface that serve to increase hydrophilicity which confirmed from our results of contact angel and swelling at equilibrium.

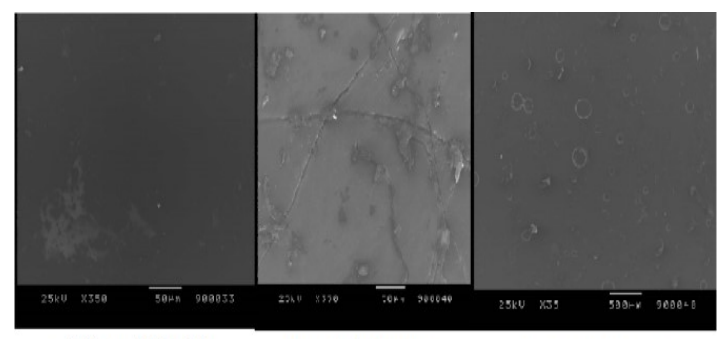

$100 \%$ pva $/ 0 \%$ Gelatin $\quad 60 \%$ PVA $/ 40 \%$ Gelatin $20 \%$ PVA $/ 80 \%$ Gelatin

Fig. (10): Surface SEM 


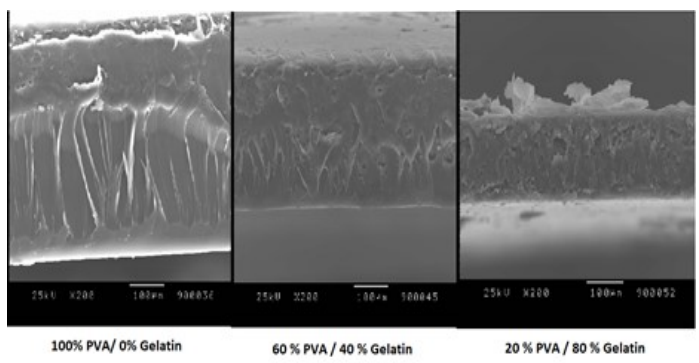

Fig. (11): Cross Sectional SEM

\section{Conclusion}

PVA/ Gelatin/ Curcumin membranes were chemically crosslinked by glutaraldehyde to wound dressing applications. FTIR, TGA and SEM analysis tools were used to describe the chemical structure of memberanes and formation of bonds between PVA and glutaraldehyde, thermal properties and surface and cross section morphologieswhich was destrored by addition of Gelatin made the membrane more hydrogel and increase swelling properties , respectively. Moreover, water-contact angle was also examined to describe the morphology. Addition of Gelatin increased hygroscopicity of memberane to save the wound wet which increase wound healing effect.

\section{Acknowledgements}

The authors extend their appreciation to the Scientific Research Fund at Tanta University, Egypt for funding this work through research project code: TU:0319-02.

\section{$\underline{\text { References }}$}

[1] Tubbs, R. K. (1966). Sequence distribution of partially hydrolyzed poly (vinyl acetate). Journal of Polymer Science Part A-1: Polymer Chemistry, 4(3), 623-629.

[2] Jones, J. I. (1973). Polyvinyl alcohol. Properties and applications. Edited by CA Finch. John Wiley, Chichester. 1973. Pp. xviii+ 622. Price: $£ 14.00$.

[3] Peppas NA, editor. Hydrogels in Medicine and Pharmacy. Boca Raton, FL: CRC Press; 1987.

[4] Johnston-Banks, F. A. (1990). Gelatin: Food Gels. Elsevier Applied Science, London, 26, 885-891.

[5] Stainsby, G. (1987). Gelatin gels. Advances in meat research (USA).

[6] Wainewright, F. W. (1977). Physical tests for gelatin and gelatin products. The science and technology of gelatin, 507-531.

[7] Gómez-Guillén, M. C., Turnay, J., Fernández-Diaz, M. D., Ulmo, N., Lizarbe, M. A., \& Montero, P. (2002). Structural and physical properties of gelatin extracted from different marine species: a comparative study. Food Hydrocolloids, 16(1), 2534.

[8] Zhou, H., S Beevers, C., \& Huang, S. (2011). The targets of curcumin. Current drug targets, 12(3), 332-347.

[9] Kenawy, E. R., Kamoun, E. A., Eldin, M. S. M., \& El-Meligy, M. A. (2014). Physically crosslinked poly (vinyl alcohol)-hydroxyethyl starch blend hydrogel membranes: Synthesis and characterization for biomedical applications. Arabian Journal of Chemistry, 7(3), 372-380. 
[10] Eldin, M. M., Hashem, A. I., Omer, A. M., \& Tamer, T. M. (2015). Wound dressing membranes based on chitosan:

Preparation, characterization and biomedical evaluation. International Journal of Advanced Research, 3(8), 908-922.

[11] Zhuang, H., Zheng, J. P., Gao, H., \& De Yao, K. (2007). In vitro biodegradation and biocompatibility of gelatin/montmorillonite-chitosan intercalated nanocomposite. Journal of Materials Science: Materials in Medicine, 18(5), 951-957.

[12] Bonilla, J., Fortunati, E. L. E. N. A., Atarés, L., Chiralt, A., \& Kenny, J. M. (2014). Physical, structural and antimicrobial properties of poly vinyl alcohol-chitosan biodegradable films. Food Hydrocolloids, 35, 463470.

[13] El Miri, N., Abdelouahdi, K., Zahouily, M., Fihri, A., Barakat, A., Solhy, A., \& El Achaby, M. (2015).
Bio-nanocomposite films based on cellulose nanocrystals filled polyvinyl alcohol/chitosan polymer blend. Journal of Applied Polymer Science, 132(22).

[14] Kolev, T. M., Velcheva, E. A., Stamboliyska, B. A., \& Spiteller, M. (2005). DFT and experimental studies of the structure and vibrational spectra of curcumin. International Journal of Quantum Chemistry, 102(6), 1069-1079.

[15] Pal, K., Banthia, A. K., \& Majumdar, D. K. (2007). Preparation and characterization of polyvinyl alcohol-gelatin hydrogel membranes for biomedical applications. Aaps Pharmscitech, 8(1), E142-E146.

\section{التشابك الكيميائي لكحول البولي فاينيل مع الجيلاتين في ضمادة الجروح المحملة بالكركمين}

أ.د الرفاعي قناوي , د. عبدالباسط شكر , زينب صابر غالي, د. محمود عطية المليجي

مجموعة أبحاث البوليمر ، كلية العلوم جامعة طنطا ، قسم الكيمياء ، طنطا ، مصر.

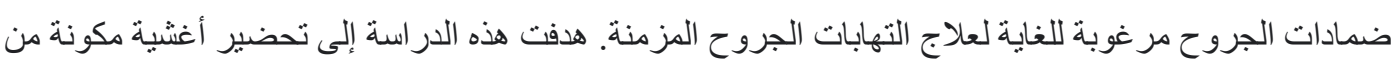
بوليمرات PVA والجيلاتين المتشابكة كيميائياً. تمت إضافة الكركمين لتحسين الخواص البيولوجية للغشاء. تم استخدام التحليل الطيفي FTIR لإظهار الهياكل الكيميائية الخاصة بهم ، بينما تم تطبيق تحليل SEM و لار اسة الثكل الخارجي للغشاء و الخواص الحرارية للأغشية المتشابكة. بالإضافة إلى ذلك ، تم إجر اء قياس زاوية التنامس أيضًا للحصول على مزيد من المعلومات حول الخصائص الفيزيائية والكيميائية بالإضافة إلى ذلك ، تم

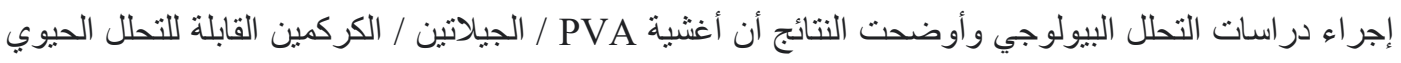
يمكن استخدامها بكفاءة كضمادة لتعزيز التئام الجروح. 